With respect to experimental games, it appears that the assumption that the primary source of reward is the individual's own outcomes is not necessarily true. As the present experiment shows, interpersonal reward comparisons may also serve as sources of reward. In analyzing the experimental game situation, it is clearly necessary to take into account interpersonal reward comparisons (e.g., Messick \& McClintock, 1968).

Since it appears that equity and unfavorable inequity can act as rewards in a two-choice situation, research is currently in progress to explore these effects on choice behavior more thoroughly, and to also examine the reward value of favorable inequity.

\section{REFERENCES}

ADAMS, J. S. Toward an understanding of inequity. Journal of Abnormal \& Social Psychology, 1963, 67, 422-436.

ADAMS, J. S. Inequity in social exchange. In L. Berkowitz (Ed.), Advances in experimental social psychology. Vol. 2. New York: Academic Press, 1965. Pp. 267-299.

Gallo, P. S., JR., \& MaClinTOCK, C. G. Cooperative and competitive behavior in mixed-motive games. Journal of Conflict Resolution, 1965, 9, 68-78.

HOMANS, C. G. Social behavior: Its elementary forms. New York: Harcourt, Brace, 1961.

MESSICK, D. M., \& MCCLINTOCK, C. G. Motivational bases of choice in experimental games. Journal of Experimental Social Psy chology, 1968, 4, 1.25.

MESSICK, D. M., \& THORNGATE, W. B. Relative gain maximization in experimental games. Journal of Experimental Social Psychology. 1967, 3, 85-101.

RADINSKY, T. L. Relative loss avoidance in the triple dominance game. Psychology, in press.

RAPOPORT, A., \& CHAMMAH, A. Sex differences in factors contributing to the level of cooperation in the Prisoner's Dilemma game. Journal of Personality \& Social Psychology, $1965,2,831-838$

\section{NOTES}

1. It should be noted that in the present experiment unfavorable inequity was consistently paired with a low outcome. This combination frequently occurs in experimental games. In addition, Messick \& Thorngate (1967) have shown that the combination of a low outcome and unfavorable inequity is a major source of influence on the pattern of interaction of individuals in a dyadic relation.

2. Actually, for half the Ss, the total accumulation of points over all trials was about $15 \%$ greater for the A2 than A1 choice. However, preliminary analysis indicated that this factor was not significant and did not interact with any other factor. Therefore, no further attention was given to this factor. Individuals are apparently not sensitive, in the present situation, to a difference as small as $15 \%$.

3. In the case of those Ss for whom the total point accumulation was $15 \%$ greater for the A2 than Al choice, the probabilities of occurrence of the 15 was .40 and that of the 4 was .60 . No changes were made with the probabilities of occurrence of the 8 and 6 . See Note 2 .

\title{
Effects of signaled time-out from and loss of monetary reinforcement on human operant behavior'
}

IRENE A. TRENHOLME, ALAN BARON, and ARNOLD KAUFMAN, University of Wisconsin-Milwaukee, Milwaukee, Wis. 53201

A signal followed by a period of time-out from reinforcement was presented while human $S$ s were responding to procure monetary reinforcement on a variableinterval schedule. The results replicated previous findings with animals of response facilitation in the presence of the signal. Facilitation also was observed when the signal preceded a brief stimulus indicating that money had been lost. The results were consistent with the hypothesis that response facilitation reflects conditioning of frustration to the signal. But it also was observed that in the majority of cases increased responding resulted in increased rates of reinforcement, thus suggesting that increased reinforcement may have been a factor in producing rate increases.

Ferster (1958) and Leitenberg (1966) used chimpanzees and pigeons to study reactions to stimuli signaling time-out from positive reinforcement. Their procedures involved pretraining on variable-interval (VI) schedules of food reinforcement and discrimination of interposed time-out periods when reinforcement was unavailable. When the time-out periods then were preceded by a signal, the characteristic reaction was heightened responding in the presence of the signal.

The present study was designed to investigate human reactions to analagous procedures. In comparison to the studies cited above, money served as the positive reinforcer, loss of positive reinforcement already gained as well as time-out was studied, and discrimination of the time-out and loss events was established through instructions.

\section{SUBJECTS AND APPARATUS}

Eight young adult college students were paid for a series of 50 -min sessions on the basis of their performance in the experimental situation. Information about the amount earned was given after each session, but actual payment occurred only at the end of the experiment. Ss sat at a table in a $6-\mathrm{ft} \mathrm{sq}$ sound-attenuated room. Located on the table was a sloping panel containing three ground-glass screens and a plastic pushbutton.

\section{INSTRUCTIONS}

Printed instructions which were in the room throughout the experiment indicated that: (a) brief green illumination of the left screen signified that 5 cents had been earned;(b) the green light would sometimes go on when the button was pressed; (c) blue illumination the center screen would serve as a signal; (d) continuous yellow illumination on the right screen signified 
that the session was in progress. For Ss in the time-out condition, the instructions also indicated that when the center screen was red, the green light could not appear. For Ss in the loss condition the instructions indicated that each time a brief red light appeared on the center screen 20 cents would be deducted from money otherwise earned during that session.

\section{BASELINE TRAINING}

To induce low rates of response, Ss initially were trained on a schedule in which the green payment signal (duration $=1 \mathrm{sec}$ ) occurred only when a response was preceded by at least $20 \mathrm{sec}$ of no responding (DRL $20 \mathrm{sec}$ ). Following 6.17 sessions, the schedule was changed to the VI $1.33-\mathrm{min}$ schedule used throughout the remainder of the experiment. Except for S4 and S5, a DRL 5-sec schedule was run concurrently with the VI baseline schedule so that programmed reinforcements were delivered only if the response was preceded by 5 sec of no responding. The stimulus subsequently used to signal time-out or loss, a 30-sec blue light on the center screen, was presented for 10-12 sessions in conjunction with the VI baseline. The blue light stimulus appeared five times per session at irregular intervals.

\section{SIGNALED TIME-OUT AND LOSS}

Following baseline training, signaled time-out or loss occurred five times each session. As before, the blue light was presented for $30 \mathrm{sec}$. The signal then went off and the center screen was illuminated with a red light. Under the time-out condition, the red light remained on for 5 min during which time reinforcement could not be obtained. Under the loss condition, the red light flashed on for $2 \mathrm{sec}$ and signified loss of 20 cents. Five Ss (1-5) were trained initially under the time-out condition and three Ss (6-8) initially under the loss condition. Following training with the loss procedure, Ss 6-8 were trained with the time-out procedure. At least 12 sessions were conducted under each condition.

\section{RESULTS}

To express the extent to which the warning signal produced changes in response rates, the ratio of rates in the presence and absence of the warning signal (excluding the loss and time-out periods themselves) was

Table 1

Ratio of Rates in the Presence and Absence of the Warning Signal

\begin{tabular}{|c|c|c|c|c|c|}
\hline \multirow[t]{2}{*}{$\mathbf{S}$} & \multirow{2}{*}{$\begin{array}{c}\text { Stimulus } \\
\text { Alone }\end{array}$} & \multicolumn{4}{|c|}{ Stimulus-TO Stimulus-Loss } \\
\hline & & $1-6$ & $7-12$ & $1-6$ & $7-12$ \\
\hline 1 & 1.13 & 1.30 & 1.58 & & \\
\hline 2 & 1.13 & 1.03 & 1.25 & & \\
\hline 3 & 1.07 & 1.12 & 1.20 & & \\
\hline 4 & 1.10 & 1.16 & 1.20 & & \\
\hline 5 & .49 & .85 & 1.25 & & \\
\hline 6 & .95 & 1.78 & 1.85 & 1.19 & .99 \\
\hline 7 & 1.04 & 1.09 & 1.03 & 1.00 & .97 \\
\hline 8 & 1.32 & 1.80 & 2.42 & 1.96 & 2.79 \\
\hline
\end{tabular}

determined for each session. Thus, a ratio above 1.00 indicated response acceleration and a ratio below 1.00 response suppression. Table 1 summarizes these values averaged for the last six sessions when only the signal was presented, for Sessions 1.6 and 7-12 when the waming signal preceded time-out (Ss 1-8), and for Sessions 1-6 and 7-12 when the warning signal preceded loss (Ss 6-8).

When the signal was not followed by either time-out or loss, the median ratio for the eight Ss was 1.09. Seven of the eight Ss showed facilitation above this level when the signal preceded time-out, both during Sessions 1-6 (median = 1.14) and Sessions 7-12 (median $=1.25)$. These increases above levels when the signal was not followed by time-oui proved statistically reliable (ps $<.05$, Wilcoxen's matched-pairs signed-ranks test).

Facilitation to the warning signal when it preceded loss was observed during Sessions 1.6 and 7.12 in two of the three Ss trained under this condition. In general, the magnitude of such facilitation was within the range observed when the signal preceded time-out.

Comparisons also were made of reinforcement rates in the presence and absence of the signal. The median ratio when the signal was presented alone was .98 . The ratio increased in two of eight Ss during Sessions 1-6 (median $=1.02)$ and in five of eight Ss during Sessions 7-12 (median $=1.10$ ), but in neither case were the increases reliable $(p s>.10)$. To determine whether there was any systematic association between response facilitation and increased reinforcement rates, rank-order correlations were computed for Sessions 1-6 and Sessions 7-12 using changes from the Stimulus-Alone phase. Although there was virtually no correlation for Sessions 1-6 $(\mathrm{Rho}=-.10)$, the correlation for Sessions 7.12 was +.66 , a value approaching the value of +.74 required for statistical significance at the $5 \%$ level of confidence (two-tailed test). To be noted in this connection is that of the seven Ss showing response facilitation during Sessions 7.12, five also obtained a greater frequency of reinforcement as a consequence while the single $S$ not showing response facilitation (S 7) also did not obtain increased reinforcement.

\section{DISCUSSION}

The results generally replicated the findings of Ferster (1958) and Leitenberg (1966) of increased responding in the presence of a signal preceding time-out. In addition, the generality of this finding was extended to situations in which: (a) human Ss were reinforced by money; (b) loss of reinforcement as well as time-out from reinforcement followed the signal; and (c) instructions were used to establish discrimination of the time-out and loss events.

Leitenberg (1966) explained heightened responding to signals of time-out from food reinforcement in terms similar to Amsel's (1958) theory of frustrative nonreward. This theory assumes that nonreward induces a drive state (frustration) with the capacity to energize ongoing behavior. In Leitenberg's study, increased operant rates in the presence of a signal preceding time-out were taken to reflect the conditioning of frustration to the signal and the energizing of concurrent operant behavior, i.e., key pecking. A similar sort of explanation may be applied to the present results. Such an account assumes that time-out from or loss of money induces a frustrative drive in human Ss which is conditioned to a signal preceding time-out or loss and which energizes ongoing behavior, i.e., key pressing.

Ferster and Leitenberg did not present data indicating whether increased response rates in the presence of the warning signal also resulted in increased reinforcement rates. Such an association would be of interest since it would support an account of response facilitation in terms of increased reinforcement rather than in terms of frustration, although obviously such correlational evidence could not establish reinforcement as the determinant of response facilitation. While initially, an association between response rates and reinforcement rates was absent in the present study, a substantial positive correlation subsequent ly appeared which approached but did not attain acceptable statistical reliability. This outcomc, then, does not permit unequivocal rejection of the hypothesis that increased reinforcement may have been a factor in the development and maintenance of response facilitation. At the least, the results show that increased reinforcement is not a necessary condition for response facilitation since response facilitation appeared in two Ss in the absence of increased rates of reinforcement.

\section{REFERENCES}

AMSEL, A. The role of frustrative nonreward in noncontinuous reward situations. Psy chological Bulletin, 1958, 55, 102-119.

FERSTER, C. B. Control of behavior in chimpanzees and pigeons by time out from positive reinforcement. Psychological Monographs, 72, 8, (Whole No. 461).

LEITENBERG, H. Conditioned acceleration and conditioned suppression in pigeons. Journal of the Experimental Analysis of Behavior, 1966, 9 , 205-212.

NOTE

1. This research constituted the first author's MS thesis and was conducted while she was a NSF Graduate Trainee. Support was provided by NSI Grants GB 4004 and GB 8234. Charles R. Shipley and Judy Kosovich assisted in the collection of the data. 